\title{
Leptin and Soluble Leptin Receptor Changes after Pulmonary Endarterectomy: Relations to Cortisol and Cytokine Network
}

\author{
P. MARUNA ${ }^{1}$, J. LINDNER ${ }^{2}$, K. M. KUBZOVÁ ${ }^{2}$ \\ ${ }^{1}$ Institute of Pathological Physiology and the Third Department of Internal Medicine, ${ }^{2}$ Second \\ Surgical Department of Cardiovascular Surgery, General Teaching Hospital and the First Faculty of \\ Medicine, Charles University, Prague, Czech Republic
}

Received February 7, 2008

Accepted May 28, 2008

On-line July 25, 2008

\begin{abstract}
Summary
Leptin is a hormone that regulates food intake. During inflammatory status, leptin may contribute to the anorexia and cachexia of infection. Pulmonary endarterectomy was used as a model of non-infectious cytokine network hyperstimulation. Leptin and soluble leptin receptor (SLR) were compared with evolution of cortisol and inflammatory cytokines in twenty-two patients with chronic thromboembolic pulmonary hypertension treated with pulmonary endarterectomy using cardiopulmonary bypass (CBP) and deep hypothermic circulatory arrest (DHCA). Leptin, SLR, cortisol, IL-1 $\beta$, IL-6, IL-8, and TNFa concentrations in arterial blood were measured before/after sternotomy, last DHCA, separation from bypass, $12,18,24,36$, and $48 \mathrm{~h}$ after sternotomy. Mean duration of CPB was 338.2 min.; mean circulatory arrest time $39.9 \mathrm{~min}$. The initial decline of leptin, SLR, TNFa, IL-6, and IL-8 was followed by an increase culminating 6$24 \mathrm{~h}$ after sternotomy. Leptin peak levels were detected $24 \mathrm{~h}$ after sternotomy $(28.0 \mathrm{ng} / \mathrm{ml}, 21.9-37.6)$. IL-6 culminated after separation from CPB, IL-8 was highest $12 \mathrm{~h}$ after sternotomy. Leptin concentrations correlated with IL-6 $(r=0.82)$, and TNFa $(r=0.73)$. Large cardiovascular surgery caused a significant increase in serum leptin, indicating its acute regulation by stress factors. This effect may be secondary to the inflammatory response mediated via cytokine stimulation. Correlation between leptin and IL-6 indicates the role of IL- 6 in leptin induction.
\end{abstract}

\section{Key words}

Leptin • Soluble leptin receptor • Interleukin-6 • Pulmonary endarterectomy • Tumor necrosis factor-a

\section{Corresponding author}

P. Maruna, Institute of Pathological Physiology, First Faculty of Medicine, Charles University, U nemocnice 5, 12808 Prague 2, Czech Republic. Fax: + 420224919 780. E-mail: maruna@LF1.cuni.cz

\section{Introduction}

Leptin, the product of the $o b$ (obese) gene, is a $16 \mathrm{kD}$ protein consisting of 146 amino acid residues. Leptin was initially described as an adipocyte-derived signaling factor that, after interaction with its receptor, induced a complex endocrine and metabolic responses including control of body weight and energy expenditure (Cakir et al. 2007, Cirmanová et al. 2008, Sirotkin et al. 2008). More recently, it was reported that leptin seems, in addition to its role in metabolic control, to have important roles in acute phase response (Křemen et al. 2006, Park et al. 2007). During inflammatory status, plasma leptin may contribute to the anorexia and cachexia of infection. Leptin may also play an important role in regulating the hypothalamo-pituitary-adrenocortical axis (Kain et al. 1999), angiogenesis and immune response.

Although body fat content is the major determinant of circulating leptin levels in rest period, other factors must contribute during inflammatory status (Maruna et al. 2006). Our previous study reported high leptin concentrations in patients with sepsis and diminished correlation of leptin and BMI in this period (Maruna et al. 2001). The potential role of proinflammatory cytokines in leptin regulation is supported by experimental findings. Limited studies have examined the possibility that tumor necrosis factor- $\alpha$ (TNF $\alpha$ ) and interleukin-6 (IL-6) could influence endocrine functions of adipose tissue, such as leptin production (Trujillo et al. 2004). Stress-induced rise in cortisol synthesis is another factor under consideration (Elimam et al. 1998).

In this study, endarterectomy of the pulmonary 
artery (PEA) was used as a model of non-infectious cytokine network hyperstimulation. PEA is a potentially curative treatment method for selected patients with chronic thromboembolic pulmonary hypertension (CTEPH), the prognosis of which would be otherwise very poor. PEA provides a significant survival advantage compared to the natural prognosis of CTEPH, medical treatment or transplant. Cardiac surgery leads to a more pronounced activation of cytokines in relation to other surgical procedures as was documented in our previous studies (Chachkhiani et al. 2005, Lindner et al. 2007). PEA is associated with hemodynamic instability in the perioperative course, suggesting the involvement of circulating mediators and cytokines as IL-1 $\beta$ and IL-6 (Comini et al. 2005, Langer et al. 2004).

The aims of this prospective study were, therefore, to characterize the time course of circulating leptin and soluble leptin receptor (SLR) in first $48 \mathrm{~h}$ after uncomplicated PEA, and to characterize the possible differences in serum leptin dynamics in relation to main inflammatory cytokines and cortisol. The plasma levels of leptin, SLR, IL-1 $\beta$, IL-6, IL-8, TNF $\alpha$, and cortisol were measured in patients during first $48 \mathrm{~h}$ after the PEA procedure.

\section{Material and Methods}

The prospective study was realized on the Second Department of Surgery - Department of Cardiovascular Surgery of the First Faculty of Medicine in Prague from January 2005 to February 2008. The ethical committee of the institution approved a study protocol and informed consent was obtained from the subjects.

\section{Patients}

Twenty-two patients - males with CTEPH (consecutive series of patients, mean age $51.7 \pm 10.8$ years, BMI $25.3 \pm 3.6 \mathrm{~kg} / \mathrm{m}^{2}$, mean \pm S.D.) with New York Heart Association (NYHA) class $3.4 \pm 0.4$, were follow with PEA. Their mean pressure in the main pulmonary artery was $52 \mathrm{~mm} \mathrm{Hg}$. The reference group for estimation of reference laboratory values consisted of 22 healthy males (48.9 \pm 8.0 years, $24.3 \pm 3.2 \mathrm{~kg} / \mathrm{m}^{2}$ ). Subjects with diabetes mellitus or hypertension were excluded form the study.

Relevant gender differences in leptin concentrations with elevated leptin levels in women have been reported. To eliminate this factor, only male patients and controls were included in our study.

\section{Surgical procedures}

Following median sternotomy, cardiopulmonary bypass (CPB) was established with cannulation of the ascending aorta and the inferior and superior vena cava (commonly at 7:30 a. m., according to a standard time schedule). Cooling began immediately using CPB cooling blankets, cooled to a bladder temperature of $18-20{ }^{\circ} \mathrm{C}$. Cardiac arrest was induced after aortic cross-clamping by infusion of cardioplegic solution (mostly St. Thomas).

Approach to the pulmonary artery had to be bilateral; both pulmonary arteries had to be substantially involved. Pulmonary artery was opened; a correct dissection plane was made and pursued to the segmental branches of pulmonary artery. For precision visualization during peripheral dissection, repeated periods of deep hypothermic circulatory arrest (DHCA) with reestablishment of $\mathrm{CPB}$ between them were necessary. After rewarming period, patient was weaned from CPB by the stepwise reduction of pump flow. Before the end of $\mathrm{CPB}$, we used an ultrafiltration of diluted blood to achieve hemoconcentration. Arterial blood pressure was continuously recorded after catheterization of a femoral artery. Hemodynamic monitoring included a surgically placed left atrial catheter in all patients and flow-directed Swan-Ganz-catheter in the PEA patients.

The standard time schedule assumed the start of surgery (sternotomy) at 8:30 a. $\mathrm{m}$. The procedure finished by weaning from $\mathrm{CPB}$ at around $4 \mathrm{p}$. m. Liquid enteral nutrition was started in all patients from second postoperative day with energy intake of $1000 \mathrm{kcal}$ per day (Isosource Standard, Novartis Nutrition GmbH, Osthofen, Germany). Intravenous infusions of saline and $5 \%$ glucose were given to correct volume and ionic dysbalance during the whole tested period.

\section{Blood samples collection}

Arterial blood samples were drawn from femoral artery catheter before operation, after sternotomy, after the last DHCA, after separation from bypass, 12, 18, 24, 36 , and $48 \mathrm{~h}$ after the onset of surgery. Blood samples of control group were drawn only at baseline. For all measurements, 5-ml of arterial blood was taken into a vacutainer tube and immediately centrifuged at $5000 \mathrm{rpm}$ for $15 \mathrm{~min}$. Plasma was stored at $-80^{\circ} \mathrm{C}$ until analysis.

Leptin, soluble leptin receptor, cortisol and cytokine analysis

Plasma levels of both leptin and soluble leptin receptor were detected by EIA tests (BioVendor 
Laboratory Medicine GmbH, Heidelberg, Germany) in duplicates. All samples were within the linear detection range. Plasma concentrations of cortisol (RIA, Orion Diagnostica, Espoo, Finland), IL-1 $\beta$, IL-6, IL-8, and TNFa (EIA, Immunotech, Paris, France) were also measured in duplicates. The intra-assay coefficients of variance were below $5 \%$.

\section{Statistical analysis}

Data were analyzed with the statistical package for social sciences, version 12.0 (SPSS Inc., Chicago, IL, USA). Analysis of covariance (ANCOVA) was used for statistical evaluation. The normal distribution of all data was examined using the Kolmogorov-Smirnov normality test to determine subsequent use of tests for statistical comparison. As variables were not normally distributed, the data were reported as median and interquartile range. Correlation between the indicators was evaluated by the Pearson's correlation coefficient and the Spearman's rank correlation. For all the tests, $\mathrm{p}<0.05$ was defined as statistically significant.

\section{Results}

Mean duration of CPB was $338.2 \pm 44.4 \mathrm{~min}$; mean duration of cross-clamping time was $126.5 \pm 20.5$ min and circulatory arrest time $39.9 \pm 7.8 \mathrm{~min}$. Extracorporeal circulation time was $338.2 \pm 44.4 \mathrm{~min}$; duration of mechanical ventilation was $51.3 \pm 36.3 \mathrm{~h}$. PEA significantly decreased the mean pressure in the main pulmonary artery (mPAP) and pulmonary vascular resistance (PVR) and increased cardiac index (CI) within first $24 \mathrm{~h}$ after surgery (Table 1 ).

Postoperative course of all tested patients was uncomplicated within $48 \mathrm{~h}$ after surgery. One patient died on the 9th day after PEA with the diagnosis of bronchopneumonia. The first clinical signs of inflammation were found on the 8th day after PEA. Subsequent autopsy proved this diagnosis. The only patient with poor prognosis did not differ from uncomplicated course in both leptin and cytokine dynamics in evaluated 48-h period after sternotomy.

The mean preoperative leptin plasma levels were $4.12 \mathrm{ng} / \mathrm{ml}$ (interquartile range, 3.19-5.22), and leptin of all tested patients was below $7.5 \mathrm{ng} / \mathrm{ml} 24 \mathrm{~h}$ before surgery. Preoperative SLR levels were $36.8 \mathrm{ng} / \mathrm{ml}$ (32.1-41.8). The mean preoperative IL-6 plasma concentrations were $21.4 \mathrm{ng} / \mathrm{ml}$ (14.1-31.5). There was no correlation between preoperative plasma levels and
Table 1. Hemodynamic status preoperatively and early after the operation.

\section{Preoperative Postoperative}

(24 h)

\begin{tabular}{|c|c|c|}
\hline$m P A P(m m ~ H g)$ & $58.0 \pm 11.7$ & $25.7 \pm 7.27 *$ \\
\hline$C I\left(\operatorname{lmin}^{-1} m^{-2}\right)$ & $1.80 \pm 0.25$ & $2.99 \pm 0.43 *$ \\
\hline PVR (dynes.s.cm $\left.{ }^{-5}\right)$ & $1162 \pm 307$ & $202 \pm 100 *$ \\
\hline
\end{tabular}

* significantly different $(p<0.001)$ from preoperative state. mPAP - mean pressure in the main pulmonary artery; CI - cardiac index; PVR - pulmonary vascular resistance.

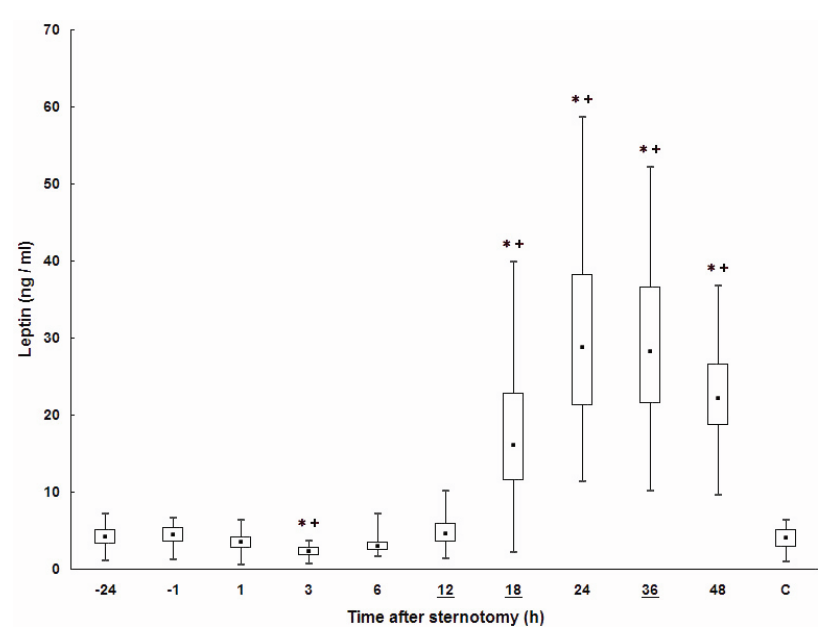

Fig. 1. Leptin dynamics in perioperative period. The same setting was used for Fig. 1 - 4: Box and whisker plot depicting the median values, interquartile range and full range. C - Control group. Underlined times correspond to samples taking in a dark period. * Significant differences $(p<0.05)$ to control group, + significant differences $(p<0.05)$ to preoperative values.

hemodynamic parameters as well as between IL-6 and hemodynamic status. All tested inflammatory parameters including IL-1 $\beta$ (4.8 ng/l, 1.2-7.7), TNF $\alpha$ (31.0 ng/l, 18.6-44.9), and IL-8 (85.0 ng/1, 38.2-128.9) did not differ from reference group $24 \mathrm{~h}$ before the start of surgery.

Arterial blood samples analysis documented a transient initial decline of leptin (minimum $3 \mathrm{~h}$ after sternotomy, $\mathrm{p}<0.01$ compared to preoperative levels) with subsequent elevation (Fig. 1). Transient initial decline of leptin correlates significantly with decrease of hematocrit during hemodilution $(r=0.76, p<0.01)$. Serum leptin levels increase postoperatively from $3 \mathrm{~h}$ after sternotomy reaching a peak level at $24 \mathrm{~h}$ after sternotomy $(28.0 \mathrm{ng} / \mathrm{ml}$, 21.9-37.6). Leptin levels were elevated in all tested patients $24 \mathrm{~h}$ after sternotomy in comparison to preoperative levels. Peak levels were significantly higher in relation to both preoperative levels and control group $(\mathrm{p}<0.001)$. 


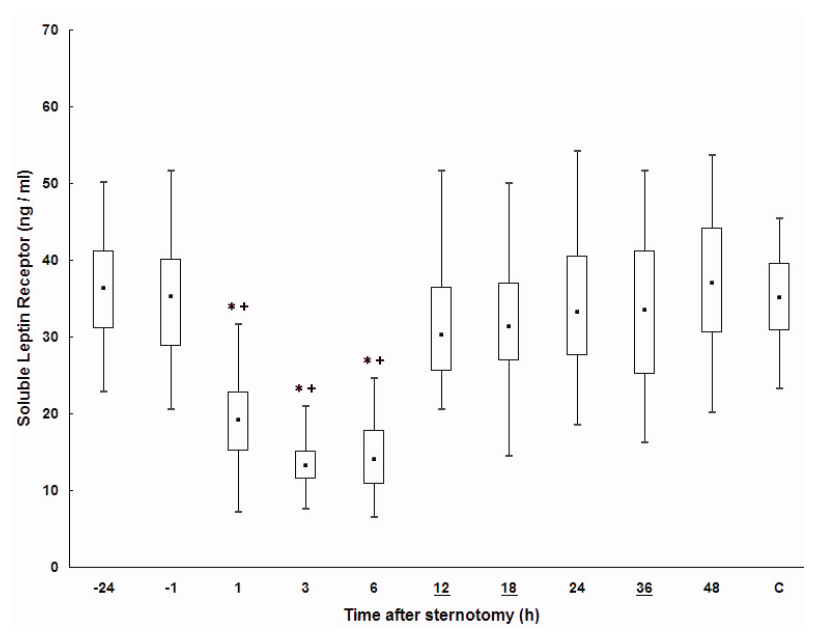

Fig. 2. Soluble leptin receptor dynamics in perioperative period.

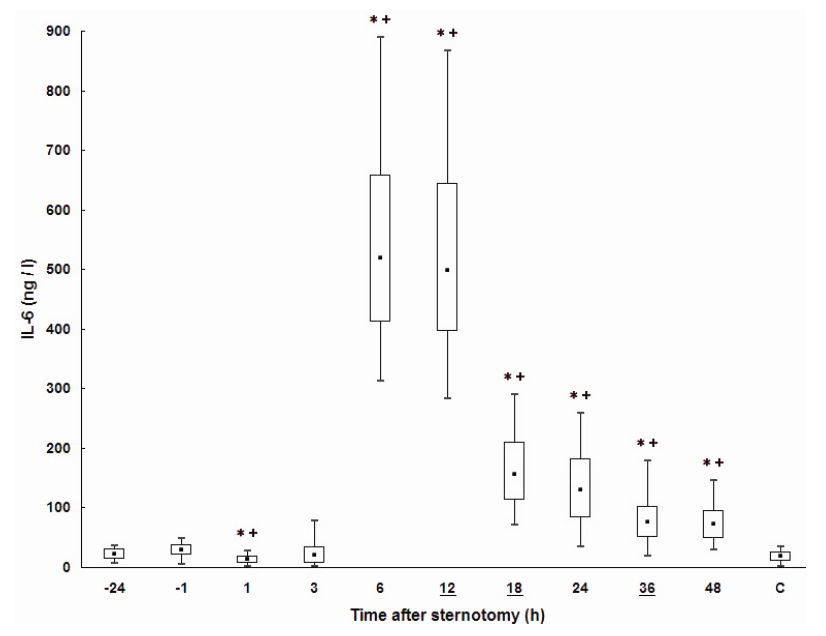

Fig. 3. IL-6 dynamics in perioperative period.

SLR dynamics is shown in Figure 2. After the start of surgery, there was a transient decline of SLR levels. Minimal SLR levels attained $3 \mathrm{~h}$ after sternotomy (13.7 ng/ml, 11.9-15.0) and they differed significantly $(p<0.01)$ from preoperative concentrations. Similarly as leptin decline, SLR decrease correlated well with changes of hematocrit during hemodilution $(\mathrm{r}=0.79, \mathrm{p}<0.01)$. SLR concentrations reverted to initial levels $12 \mathrm{~h}$ after start of surgery.

The same initial decrease was also revealed for IL-6 (Fig. 3), IL-8, and TNFa. Peak levels of IL-6 were reached $6 \mathrm{~h}$ after CPB (524.2 ng/1, 418.0-668.2) and the same was true for TNF $\alpha$ culmination (154.2 ng/1, 97.2228.3). IL-8 culminated later, $12 \mathrm{~h}$ after sternotomy (438.0 ng/1, 264.2-644.9). IL-1 $\beta$ elevation with maximum $6 \mathrm{~h}$ after start of surgery was not significantly different from initial levels.

Preoperative plasma cortisol levels measured by RIA were $411.6 \mathrm{ng} / \mathrm{l}$ (318.1-485.2). Without initial



Fig. 4. Plasma cortisol dynamics in perioperative period.

decrease shown in other parameters, cortisol concentrations culminated $6 \mathrm{~h}$ after sternotomy (1462.7 $\mathrm{ng} / \mathrm{l}, 1102.6-1879, \mathrm{p}<0.001$ in relation to both reference group and preoperative status). Despite following decrease, cortisol remained elevated $48 \mathrm{~h}$ after start of surgery (Fig. 4).

Postoperative peak values of leptin and IL-6 correlated closely $(\mathrm{r}=0.82, \mathrm{p}<0.01)$. Significant correlation was also found for peak values of leptin and $\mathrm{TNF} \alpha(\mathrm{r}=0.73, \mathrm{p}<0.01)$. Correlation between leptin and other cytokines was not significant. No correlation was found between plasma cortisol and leptin levels. There was attenuated correlation of plasma leptin and BMI during first $24 \mathrm{~h}$ after surgery: $\mathrm{r}=0.775 ; \mathrm{p}<0.01$ before operation, $\mathrm{r}$ $=0.48 ; \mathrm{p}<0.05$ in samples $24 \mathrm{~h}$ after the start of surgery. No correlation was found between plasma leptin levels and mean arterial blood pressure or between plasma leptin and creatinine levels in postoperative period.

No significant correlation was revealed between SLR concentrations and tested inflammatory.

\section{Discussion}

Presented results demonstrate the evolution of leptin and SLR in relation to a large cardiovascular surgery with deep hypothermia and circulatory arrest. It has been previously shown that leptin change postoperatively (Křemen et al. 2006, Maruna et al. 2005) and leptin evolution is related to inflammatory status. Cardiac surgery leads to a more pronounced activation of cytokines than other surgical procedures (Dörge et al. 2003). This cytokine 'burst' mediates a systemic response by the body's inflammatory system, well-known as the systemic inflammatory response syndrome (SIRS) 
(Giamarellos-Bourboulis et al. 2004). Therefore PEA represents a suitable clinical model of cytokine network hyperstimulation without contribution of infectious factor.

Several factors may influence the evolution of serum leptin levels after cardiac surgery in the absence of postoperative complications. The combination of CPB, local trauma, deep hypothermia, and pulmonary and myocardial reperfusion leads to substantial changes in the immune system. Our findings are consistent with the hypothesis that cytokine network influences the leptin secretion. Positive correlation between leptin and IL-6, as well as between leptin and TNF $\alpha$ indicates the role of both cytokines in leptin induction in perioperative phase.

Trujillo et al. (2006) suggesteed that high systemic TNF may contribute to increased leptin production during stress. TNF $\alpha$ and glucocorticoids synergistically increase leptin production in human adipocytes. Synergistic effects of local or systemic TNF or IL-6 in combination with glucocorticoids may contribute to increased leptin expression in response to surgical stress as was seen in our study. Present study did not address the mechanism of the interaction of TNF $\alpha$ and IL-6 with leptin production. However, it appears that both cytokines increase leptin most markedly in the presence of glucocorticoids. From a physiologic point of view, synergistic effects of glucocorticoids and IL-6 on leptin suggest a role in stress-induced increases in leptin production (Trujillo et al. 2004).

Plasma levels of cortisol increased in tested group, but without significant correlation to leptin levels. Glucocorticoids are known to up-regulate serum leptin, and are reported to amplify the in vitro up-regulation of leptin by other factors (Elimam et al. 1998). This is hypothesized that the rise in serum cortisol observed after surgery enhanced the effect of inflammatory factors. The effects of cytokines on leptin in man are still controversial. Unchanged serum leptin levels after high doses of prednisolone given to healthy volunteers have also been reported (Tataranni et al. 1997), and it has been discussed whether the effects of glucocorticoids on leptin in humans are restricted to acute pharmacological dosing.

Even high cortisol values observed in our patients did not prevent the activation of TNF $\alpha$ and IL- 6 . Cortisol is the major regulator of the expression and action of pro-inflammatory cytokines limiting the amplitude and duration of SIRS. Through the release of the anti-inflammatory cytokines as IL-10, cortisol prevents indirectly the further synthesis of pro- inflammatory mediators. The time course of proinflammatory cytokines after surgery is thus determined by the interaction of stimulatory factors (tissue trauma, CPB, hypothermia) and endogenous inhibitors on both local and systemic levels.

Significant correlation between leptin and IL-6 was found in our study. Park et al. (2007) recently demonstrated the same relation between leptin and IL-6 in other model of non-infectious inflammatory reaction ankylosing spondylitis. Serum leptin levels were increased and significantly associated with IL-6 levels. Both indicate that IL-6 can be a regulator of leptin generation in early postoperative period. As was described by Trujillo et al. (2004), IL-6 had no significant effects in vitro under basal conditions, but the combination of IL-6 and dexamethasone, compared with dexamethasone alone, increased leptin production twofold. It is possible that pro-inflammatory cytokines induce $o b$ gene transcription in vivo through secondary mediators such as transforming growth factor $\beta$ (Granowitz 1997).

Results document that leptin culmination is delayed in alignment to pro-inflammatory mediators as IL- 6 and TNF $\alpha$. Both mentioned cytokines are assumed to activate leptin induction in vivo. The following decline of leptin levels $48 \mathrm{~h}$ after surgery corresponds to the absence of a further insult that may induce more leptin production. The lack of correlation between leptin and IL-1 $\beta$ plasma levels in our patients may be explained by prevailing local activities of this cytokine. Plasma 'overflow' of IL-1 $\beta$ and other cytokines during SIRS does not reflect their tissue expression directly. Especially IL$1 \beta$ showed only mild elevation bellow statistical significance in postoperative period.

The main limitation of our study is a potential role of nutritional factors in leptin dynamics. The changes observed in leptin concentrations could be affected by the reduced food intake in our patients. To eliminate this factor may be difficult in clinical conditions. Both experimental and clinical studies showed that fasting inhibits leptin production. We suppose that short periods of fasting and surgical stress can sensitize the leptin response to stimulatory factors. In summary, both shortterm fasting and stress-related cortisol elevation might constitute a background for leptin reactivity to inflammatory mediators. The experimental results of Trujillo et al. (2004) supported this concept.

Leptin receptor was found to be a member of the class I cytokine receptor family. Alternate splicing from a single gene derives the six isoforms of both membrane 
bound and soluble receptors. SLR levels are indirectly proportional to adiposity and are increased in females compared to males. Many different physiological and pathophysiological conditions, e.g. adiposity, sex steroids, and leptin independently regulate plasma SLR. Soluble receptors control the amount of free leptin and the rate of leptin clearance (Zastrow et al. 2003). Therefore changed SLR levels may modulate the actions of leptin in tissues (Cohen et al. 2007).

Our data showed that SLR is not an acute phase reactant in postoperative period. Voegeling and Fantuzzi (2001) reported increased levels of SLR during inflammation in mice. Other studies did not support their findings, and this question was not clarified, yet. Schoff et al. (2003) demonstrated no influence of surgical stress on postoperative soluble leptin receptor plasma levels and their finding are in conformity with our results.

Significant transient initial decline of both leptin and SLR after surgery can be explained mostly by hemodilution. Significant correlation between leptin and hematocrit demonstrated this phenomena. We suspect the role of hemofiltration as another factor affecting biphasic leptin course in perioperative phase. Hemofiltration is used for hemoconcentration at the end of the operation. This biphasic postoperative course was not limited to leptin and SLR. The tendency to transitory decrease after start of surgery was revealed in all tested parameters, but without statistical significance except of IL-6.

Leptin is structurally similar to granulocyte colony-stimulating factor, member of IL-6 cytokine family. It has been reported that leptin can induce proliferation, differentiation, and functional activation of hemopoietic cells and can enhance the proliferation and phagocytic activity of macrophages (Loffreda et al. 1998,
Santos-Alvarez et al. 1999). These results identify an important and novel function for leptin: up-regulation of inflammatory immune responses. However its physiological importance in acute phase reaction remains unclear. Induction of leptin during the surgical stress response may contribute to the wound healing, anorexia, and activation of hematopoiesis. These and other effects were reported in experimental studies.

In summary, large cardiovascular surgery caused a more than sixfold increase in serum leptin. Postoperative leptin culmination was delayed in alignment to pro-inflammatory mediators. The positive correlation between leptin and IL-6 indicate that the above mentioned cytokine plays a role in leptin induction. This mechanism is similar to other models of SIRSinduced cytokine network.

\section{Conflict of Interest}

There is no conflict of interest.

\section{Acknowledgements}

Supported with grant IGA MZ NR9223-3 of the Ministry of Health, Czech Republic and VZ MSM0021620819.

\footnotetext{
Abbreviations

BMI - body mass index, CI - cardiac index, CPB cardiopulmonary bypass, $\mathrm{CRP}-\mathrm{C}$ reactive protein, $\mathrm{CTEPH}-$ chronic thromboembolic pulmonary hypertension, DHCA - deep hypothermic circulatory arrest, IL - interleukin, mPAP - main pulmonary artery pressure, PEA - pulmonary endarterectomy, PVR pulmonary vascular resistance, SIRS - systemic inflammatory response syndrome, SLR - soluble leptin receptor, TNF $\alpha$ - tumor necrosis factor- $\alpha$
}

\section{References}

CAKIR B, KASIMAY O, DEVSEREN E, YEGEN BC: Leptin inhibits gastric emptying in rats: role of CCK receptors and vagal afferent fibers. Physiol Res 56: 315-322, 2007.

CIRMANOVÁ V, BAYER M, STÁRKA L, ZAJÍČKOVÁ K: The effect of leptin on bone - an evolving concept of action. Physiol Res 57 (Suppl 1): S143-S151, 2008.

COHEN SE, KOKKOTOU E, BIDDINGER SB, KONDO T, GEBHARDT R, KRATZSCH J, MANTZOROS CS, KAHN CR: High Circulating Leptin Receptors with Normal Leptin Sensitivity in Liver-specific Insulin Receptor Knock-out Mice. J Biol Chem 282: 23672-23678, 2007.

COMINI L, PASINI E, BACHETTI T, DREANO M, GAROTTA G, FERRARI R: Acute haemodynamic effects of IL6 treatment in vivo: involvement of vagus nerve in NO-mediated negative inotropism. Cytokine 30: 236-242, 2005.

DÖRGE H, SCHONDUBE FA, DORGE P, SEIPELT R, VOSS M, MESSMER BJ: Procalcitonin is a valuable prognostic marker in cardiac surgery but not specific for infection. Thorac Cardiovasc Surg 51: 322-326, 2003. 
ELIMAM A, KNUTSSON U, BRÖNNEGARD M, STIERNA P, ALBERTSSON-WIKLAND K, MARCUS C: Variation in glucocorticoids within the physiological range affect plasma leptin levels. Eur J Endocrinol 139: 615-620, 1998.

GIAMARELLOS-BOURBOULIS EJ, GIANNOPOULOU P, GRECKA P, VOROS D, MANDRAGOS K, GIAMARELLOU H: Should procalcitonin be introduced in the diagnostic criteria for the systemic inflammatory response syndrome and sepsis? J Crit Care 19: 152-157, 2004.

GRANOWITZ EV: Transforming growth factor-beta enhances and pro-inflammatory cytokines inhibit ob gene expression in 3T3-L1 adipocytes. Biochem Biophys Res Commun 240: 382-385, 1997.

CHACHKHIANI I, GURLICH R, MARUNA P, FRASKO R, LINDNER J: The postoperative stress response and its reflection in cytokine network and leptin plasma levels. Physiol Res 54: 279-285, 2005.

KAIN ZN, ZIMOLO Z, HENINGER G: Leptin and the perioperative neuroendocrinological stress response. $J$ Clin Endocrinol Metab 84: 2438-42, 1999.

KŘEMEN J, DOLINKOVÁ M, KRAJIČKOVÁ J, BLÁHA J, ANDERLOVÁ K, LACINOVÁ Z, HALUZÍKOVÁ D, BOŠANSKÁ L, VOKURKA M, SVAČINA S, HALUZÍK M: Increased subcutaneous and epicardial adipose tissue production of proinflammatory cytokines in cardiac surgery patients: possible role in postoperative insulin resistance. J Clin Endocrinol Metab 91: 4620-4627, 2006.

LANGER F, SCHRAMM R, BAUER M, TSCHOLL D, KUNIHARA T, SCHAFERS HJ. Cytokine response to pulmonary thromboendarterectomy. Chest 126: 135-141, 2004.

LINDNER J, MARUNA P, BLÁHA J, JANSA P, GÜRLICH R, GRUS T, KUNŠTÝŘ J, ASCHERMANN M, LINHART A, STRÁŽNICKÝ M, TOŠOVSKÝ J: Cytokine response in patients with CTEPH undergoing pulmonary endarterectomy. Abstracts of the 5th Annual Current Trends in Cardiothoracic Surgery, Houston, 2007.

LOFFREDA S, YANG SQ, LIN HZ, KARP CL, BRENGMAN ML, WANG DJ, KLEIN AS, BULKLEY GB, BAO C, NOBLE PW, LANE MD, DIEHL AM: Leptin regulates proinflammatory immune responses. FASEB J 12: 5765, 1998.

MARUNA P, GÜRLICH R, FRAŠKO R, HALUZÍK M: Serum leptin levels in septic men well correlate with Creactive protein and TNF-alpha but not with BMI. Physiol Res 50: 589-594, 2001.

MARUNA P, GÜRLICH R, FRAŠKO R, ROSICKÁ M: Ghrelin and leptin elevation in postoperative intra-abdominal sepsis. Eur Surg Res 37: 354-359, 2005.

MARUNA P, GÜRLICH R, FRAŠKO R, CHACHKHIANI I: Leptin in acute phase response. In: Body Mass Index and Health. LA FERRERA (ed), Nova Science Publishers, Hauppauge, NY, 2006, pp 97-117.

MARUNA P, FRAŠKO R, GÜRLICH R: Plasma procalcitonin in patients with ileus. Relations to other inflammatory parameters. Physiol Res 57: 481-486, 2008.

PARK MC, LEE SW, CHOI ST, PARK YB, LEE SK: Serum leptin levels correlate with interleukin-6 levels and disease activity in patients with ankylosing spondylitis. Scand J Rheumatol 36: 101-106, 2007.

SANTOS-ALVAREZ J, GOBERNA R, SANCHEZ-MARGALET V: Human leptin stimulates proliferation and activation of human circulating monocytes. Cell Immunol 194: 6-11, 1999.

SCHOOF E, STUPPY A, HARIG F, SINGER H, CARBON R, HORBACH T, KRATZSCH J, RASCHER W, DÖTSCH J: No influence of surgical stress on postoperative leptin gene expression in different adipose tissues and soluble leptin receptor plasma levels. Horm Res 59: 184-190, 2003.

SIROTKIN AV, MLYNČEK M, MAKAREVICH AV, FLORKOVIČOVÁ I, HETÉNYI L: Leptin affects proliferation-, apoptosis- and protein kinase A-related peptides in human ovarian granulosa cells. Physiol Res 57: 437-442, 2008.

TATARANNI PA, PRATLEY R, MAFFEI M, RAVUSSIN E: Acute and prolonged administration of glucocorticoids (methylprednisolone) does not affect plasma leptin concentration in humans. Int J Obes Relat Metab Disord 21: 327-330, 1997.

TRUJILLO ME, SULLIVAN S, HARTEN I, SCHNEIDER SH, GREENBERG AS, FRIED SK: Interleukin-6 regulates human adipose tissue lipid metabolism and leptin production in vitro. J Clin Endocrinol Metab 89: 5577-5582, 2004. 
TRUJILLO ME, LEE MJ, SULLIVAN S, FENG J, SCHNEIDER SH, GREENBERG AS, FRIED SK: Tumor necrosis factor alpha and glucocorticoid synergistically increase leptin production in human adipose tissue: role for p38 mitogen-activated protein kinase. J Clin Endocrinol Metab 91: 1484-1490, 2006.

VOEGELING S, FANTUZZI G: Regulation of free and bound leptin and soluble leptin receptors during inflammation in mice. Cytokine 14: 97-103, 2001.

ZASTROW O, SEIDEL B, KIESS W, THIERY J, KELLER E, BOTTNER A, KRATZSCH J: The soluble leptin receptor is crucial for leptin action: evidence from clinical and experimental data. Int $J$ Obes Relat Metab Disord 27: 1472-1478, 2003. 